\title{
Molecular Characterization of Some Genetic Factors Controlling Spermatogenesis in Egyptian Patients with Male Infertility
}

Alaaeldin Gamal Fayez, Amr Saad El-Sayed, Mohamed Ali El-Desouky, Waheba Ahmed Zarouk, Alaa Khalil Kamel, Ibrahim Mohamed Fahmi, Mona Omar El-Ruby

\begin{abstract}
Men with severe infertility suffer a high risk of $Y$ chromosome deletion, hence screening for these cases is recommended prior to treatment with assisted reproduction. Our study aimed to investigate and detect the azoospermia factor (AZF) region deletion, rearrangement and deleted azoospermia (DAZ) gene copy number variations in Egyptian azoospermic infertile men. This was tested on 54 Egyptian nonobstructive azoospermic (NOA) infertile men, with age ranged from 21 to 45 years (mean: $31.4 \pm 6.1$ years), by STS \pm multiplex PCR using a set of 14 sequence tagged sites (STSs) from three different regions of the Y chromosome: AZFa, AZFb, AZFc and sY587/Dral PCRRFLP assay to determine DAZ copy number variations. The results revealed a significant prevalence of AZFc subtypes deletion and reduced DAZ gene dosage in Egyptian azoospermic cases affecting $Y$ chromosome deletions. To our knowledge, this study is the first one to investigate AZFC subtypes deletion and DAZ gene dosage in Egyptian infertile men. We concluded that DAZ genes deletion is a risk factor for spermatogenic damage.
\end{abstract}

Keywords: Spermatogenesis, AZF, DAZ, Nonobstructive azoospermia.

How to cite this article: Fayez AG, El-Sayed AS, El-Desouky MA, Zarouk WA, Kamel AK, Fahmi IM, El-Ruby MO. Molecular Characterization of Some Genetic Factors Controlling Spermatogenesis in Egyptian Patients with Male Infertility. Int J Infertility Fetal Med 2012;3(3):69-77.

Source of support: National Research Centre, Egypt.

Conflict of interest: None

\section{INTRODUCTION}

Primary infertility is the inability of a sexually active, noncontracepting couple to achieve pregnancy in 1 year. ${ }^{1}$ This is considered a major reproductive health problem today that affects 10 to $22 \%$ of couples in the human population. In about 50\% of these couples, the underlying problem lies in the male, either solely or in combination with female factor. $^{2-5}$

Screening for Y chromosome microdeletions before intracytoplasmic sperm injection is often underdetermined. Therefore, the present study is aimed to investigate the

Date of Received: $10-10-12$

Date of Acceptance: 12-10-12

Date of Publication: September 2012 frequencies of Y chromosome microdeletion, definitely in azoospermia factor (AZF), in Egyptian nonobstructive azoospermic (NOA) infertile men. Furthermore, the present study was designed to determine the frequency of copy number variations of one of testis specific genes named deleted azoospermia (DAZ) gene that is confirmed by AZFc rearrangement.

\section{MATERIALS AND METHODS}

Male subjects with primary infertility attending the clinical genetics clinic at the National Research Centre (NRC) and andrology clinic at the Kasr Al Ainy Hospital, Cairo University (Egypt), were enrolled in the present study after ensuring that they are NOA. All tests using human samples were carried out with informed consent according to ethical committee instructions of NRC.

\section{SELECTION OF CASES}

During January 2011 to September 2012, a total of 54 cases with azoospermia were studied according to selection criteria, including only cases suffering of primary infertility, in a middle reproductive age (20-45 yrs), had repeated seminal analysis (two at least, to ensure that they are azoospermic even after centrifugation), performed karyotypes to classify the cases to group having chromosomal aberration and another not having chromosomal aberration. All the included cases signed the informed consent. Exclusion criteria included cases with varicocele, obstruction of the seminal tract, pituitary failure or any other causes of testicular damage or exposure to infection or radiation.

Thirty fertile control cases, matched with respect to age, were selected as control group. All members of the control group were healthy men with normal reproductive history (with one or more children in the last 3 years), normal physical examination and normal sperm concentration (more than $15 \times 106 \mathrm{spz} / \mathrm{ml})$.

\section{CLINICAL EVALUATION}

Each patient was carefully examined clinically to rule out other causes of infertility. A detailed family, occupational 
and reproductive history were evaluated. Pedigree analysis for three generations was constructed to rule out consanguinity. Specific and local examination of the external genitalia with scoring the testicular size using the orchidometer, penile length, size and scrotal development were evaluated.

Signs of Klinefelter (KF) syndrome were reported for each case mainly; tall stature, underdeveloped of secondary sexual characters, testicular atrophy, feminine distribution of fat and others.

\section{CYTOGENETIC STUDIES}

Peripheral blood lymphocyte cultures and G-banding technique were done for 54 patients according to the standard method. ${ }^{6}$ High resolution using method of synchronization was done according to the method of Yunis et $\mathrm{al}^{7}$ for some cases. A total of 25 metaphases were analyzed for each case. Any structural or numerical anomalies were recorded and karyotyped according to the ISCN. ${ }^{8}$

\section{GENOMIC DNA EXTRACTION}

Blood samples were collected using Na2EDTA as anticoagulant inside vacutainer sterile tubes. DNA was isolated from peripheral blood leukocytes by QIAamp DNA Mini Kit (50 prep), cat no. 51304, Germany.

\section{AZF MAPPING}

The European Academy of andrology and the European Molecular Genetics Quality Network (EAA/EMQN) guidelines indicate that the use of six STS loci (sY84, sY86, sY127, sY134, sY254, sY255) result in the detection of up to $95 \%$ of all reported Y-chromosome microdeletions in the AZF regions. ${ }^{9}$ Additional STS loci can then be used to define the deletion breakpoints further. An STS was considered absent only after at least two amplifications failure in the presence of successful amplification of control (SRY-sY14).

So, mapping three regions of AZF [AZFa, AZFb and AZFc on most long (q) arm of Y chromosome] was carried out through three stages as follows:

\section{Stage I-Mapping of Yq Classical Deletions}

Investigation of AZFa, AZFb and AZFc microdeletions was done using six STSs loci \pm multiplex PCR analysis according to EAA/EMQN best practice guidelines for molecular diagnosis of Y-chromosomal microdeletions. ${ }^{9}$ These STS primers have been shown to give robust and reproducible results in multiplex PCR reactions by several laboratories and in external quality control trials and these are clinically relevant STSs to azoospermia condition.
The SRY gene, testis-determining factor on the short arm of the $\mathrm{Y}$ chromosome, was included in the analysis as an internal control for the presence of Y-specific AZF sequences and for absent $\mathrm{Y}$ chromosome (e.g. in XX males). A DNA sample from a fertile male and a blank (water) control was run in parallel with each multiplex PCR.

\section{Stage II-Detection of DAZ Copy Number Variations}

According to Lin et $\mathrm{al}^{10}$ a combination of the DAZ dosage PCR and the STS multiplex PCR reaction detects most, if not all, deletions and duplications at AZFc, so this stage aimed to deep investigation of most relevant AZFc genes to spermatogenic disturbance through investigation of DAZ gene copy number variations for cases outcoming from stage I who had sY255 and sY254. Investigation was carried out using single nucleotide variants (SNVs) PCR analysis. After subsequent confirmation of amplification of sY587, the copy number variation analysis was accomplished by sY587/DraI PCR-RFLP (Table 1).

The PCR product was digested by fast digest DraI restriction enzyme for 5 minutes at $37^{\circ} \mathrm{C}$. Finally, the digested products were run on a $3 \%$ agarose gel containing ethidium bromide and visualized by UV transilluminator.

\section{Stage III-Typing of AZFc Subdeletions}

This stage aimed to confirm the results of stage II through AZFc rearrangements analysis using seven AZFc-specific sequence tagged sites (STSs) (sY1191, sY1291, sY1206, sY1201, sY1258, sY1054, sY1161) to identify the subtypes of AZFc deletions. The AZFc rearrangement analysis results were interpreted according to Table $2 .{ }^{11-14}$

Detailed sequences of the all primers that used in molecular studies were given in Table 3.

\section{STATISTICAL ANALYSIS}

Statistical analysis was performed using the statistical package SPSS for Windows (version 17; SPSS, Chicago, IL, USA). Data were presented as frequencies and statistical evaluation was performed by Chi-squared test $\left(\chi^{2}\right)$ to statistic the significance of differences among these frequencies.

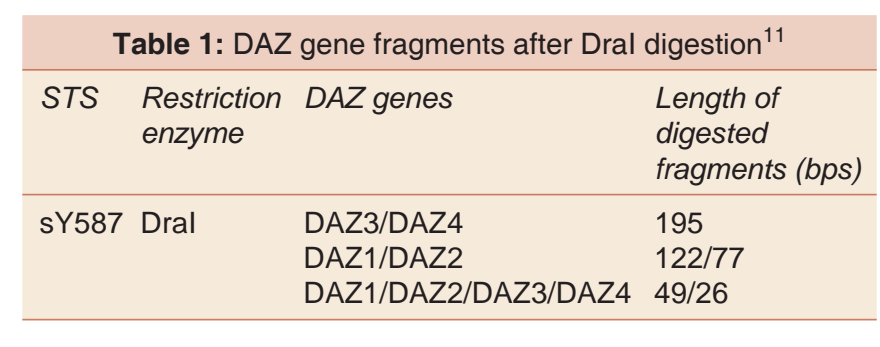


Molecular Characterization of Some Genetic Factors Controlling Spermatogenesis in Egyptian Patients with Male Infertility

\begin{tabular}{|c|c|c|c|c|c|c|c|}
\hline sY1258 & $s Y 1161(\times 2)$ & sY1191 & sY1291 & sY1206 (×2) & sY1054 & sY1201 & Subdeletion types \\
\hline+ & + & + & - & + & + & + & $\mathrm{gr} / \mathrm{gr}$ \\
\hline+ & + & - & + & + & + & + & b2/b3 \\
\hline+ & + & + & + & - & - & + & b3/b4 \\
\hline+ & - & - & - & + & + & + & b1/b2 \\
\hline+ & + & - & - & - & - & + & b2/b4 \\
\hline
\end{tabular}

\begin{tabular}{|c|c|c|c|c|}
\hline STS & Forward (5'-3') & Reverse (5'-3') & $\begin{array}{l}\text { Amplicon } \\
\text { size (bps) }\end{array}$ & Y region \\
\hline \multicolumn{5}{|c|}{ Mapping of Yq classical deletion primers } \\
\hline SRY & GAA TAT TCC CGC TCT CCG GA & GCT GGT GCT CCA TTC TTG AG & 214 & $\mathrm{P}$ arm \\
\hline sY86 & GTG ACA CAC AGA CTA TGC TTC & ACA CAC AGA GGG ACA ACC CT & 320 & AZFa \\
\hline sY127 & GGC TCA CAA ACG AAA AGA AA & CTG CAG GCA GTA ATA AGG GA & 274 & $\mathrm{AZFb}$ \\
\hline sY254 & GGG TGT TAC CAG AAG GCA AA & GAA CCG TAT CTA CCA AAG CAG C & 400 & AZFc \\
\hline sY84 & AGA AGG GTC TGA AAG CAG GT & GCC TAC TAC CTG GAG GCT TC & 326 & $\mathrm{AZFa}$ \\
\hline sY134 & GTC TGC CTC ACC ATA AAA CG & ACC ACT GCC AAA ACT TTC AA & 301 & $\mathrm{AZFb}$ \\
\hline sY255 & GTT ACA GGA TTC GGC GTG AT & CTC GTC ATG TGC AGC CAC & 126 & AZFc \\
\hline \multicolumn{5}{|c|}{ Typing of AZFc subdeletion primers } \\
\hline sY1054 & ACC TAA GGG AAC CCA GGA GA & CGA CAC TTT TGG GAA GTT TCA & 340 & AZFc \\
\hline sY1201 & CCG ACT TCC ACA ATG GCT & GGG AGA AAA GTT CTG CAA CG & 677 & AZFC \\
\hline sY1206 & ATT GAT CTC CTT GGT TCC CC & GAC ATG TGT GGC CAA TTT GA & 394 & AZFC \\
\hline sY1161 & CGA CAC TTT TGG GAA GTT TCA & TTG TGT CCA GTG GTG GCT TA & 330 & AZFc \\
\hline sY1191 & CCA GAC GTT CTA CCC TTT CG & GAG CCG AGA TCC AGT TAC CA & 385 & AZFC \\
\hline sY1258 & AAC CCC ATC TCT AGC AAA AAT ATG & TAG GTG ACA GGG CAG GAT TC & 968 & AZFC \\
\hline sY1291 & TAA AAG GCA GAA CTG CCA GG & GGG AGA AAA GTT CTG CAA CG & 527 & AZFc \\
\hline \multicolumn{5}{|c|}{ Detection of DAZ copy number variations primer } \\
\hline sY587 & TGG TTA ATA AAG GGA AGG TGT TTT & TCT CCA GGA CAG GAA AAT CC & 270 & AZFc \\
\hline
\end{tabular}

AZF: Azoospermia factor; STS: Sequence tagged site

\section{ETHICAL CONSIDERATIONS}

- Written consent was taken from every case sharing in the study.

- The participants were informed about the purpose of the study.

- All the steps of the tests were explained to the patient with all its possible complications.

- All patients' clinician data and test results are confidential.

\section{RESULTS}

- Clinical analysis: The mean age of cases was $31.4 \pm$ 6.1 years (range: 21-45 years). Examination of the external genitalia and signs of KF syndrome revealed that 12 of 54 studied NOA cases (22.2\%) had signs of KF syndrome as shown in Table 4.

- Karyotyping analysis: The karyotyping analysis aimed to classify the azoospermic cases to two groups; Azoospermic infertile men with chromosomal aberration and other ones without chromosomal aberration. Therefore, chromosomal studies showed KF syndrome
(47, XXY) in 12/54 (22.2\%) and 39 cases without KF syndrome (72.2\%), one case had 46, X invY (q11.21 q11.22) and two cases had XX male. Among $12 \mathrm{KF}$ syndrome cases, 11 were diagnosed as nonmosaic $(11 / 12,91.7 \%)$ and one case diagnosed as mosaic (1/12, 8.3\%), as shown in Table 5.

- Yq mapping analysis: Mapping of Yq region revealed AZF aberration in 11 cases (11/54, 20.4\%). Among them, 10 cases had AZFc aberrations (10/11, 90.9\%) and one case had partial AZFa+b deletion (1/11, 9.1\%). Among 10 azoospermic cases with AZFc aberrations, three cases had complete AZFc deletion (3/10, 30\%) with DAZ1/2/3/4 deletion, two cases (46, XX male with positive SRY gene) had complete AZF deletion including all AZFc region (2/10, 20\%), five cases had only DAZ1/2 loss (5/10, 50\%) and no cases had only DAZ3/4 loss. It was found that all 10 cases which had AZFc aberrations had DAZ1/2 deletion.

From combining molecular and karyotyping data, we found no significant difference between frequency of sex chromosomal anomalies and frequency of sex 


\begin{tabular}{|c|c|c|c|c|}
\hline$I D$ & Age (years) & Testicular atrophy & Height & Gynecomastia (breast tissue) \\
\hline 3 & 31 & Severe bilateral & Mean & $-v e$ \\
\hline 10 & 31 & Severe bilateral & Mean & $-v e$ \\
\hline 12 & 26 & Severe bilateral & Mean & $-v e$ \\
\hline 13 & 45 & Severe bilateral & Mean & $-v e$ \\
\hline 16 & 35 & Mild right & Mean & $-v e$ \\
\hline 17 & 39 & Severe bilateral & Mean & $-v e$ \\
\hline 18 & 23 & Severe bilateral & Mean & $-v e$ \\
\hline 19 & 30 & Severe bilateral & Mean & $-v e$ \\
\hline 23 & 21 & Mild bilateral & Mean & $-v e$ \\
\hline 24 & 26 & Severe bilateral & Mean & $-v e$ \\
\hline 26 & 28 & Mild bilateral & Mean & $-v e$ \\
\hline 27 & 27 & Mild bilateral & Tall & $-v e$ \\
\hline
\end{tabular}

\begin{tabular}{cccc}
\multicolumn{2}{c}{ Table 5: Results of karyotypes among the studied infertile male cases } \\
\hline Cases ID & Age (years) & Karyotyping & AZF deletion \\
\hline 3 & 31 & $47, \mathrm{XXY}$ & No \\
10 & 31.5 & $47, \mathrm{XXY}$ & No \\
12 & 26 & $47, \mathrm{XXY}$ & No \\
13 & 45 & $47, \mathrm{XXY}$ & No \\
16 & 35 & $47, \mathrm{XXY}(75 \%) ; 46, \mathrm{XY}(25 \%)$ & No \\
17 & 39 & $47, \mathrm{XXY}$ & No \\
18 & 23 & $47, \mathrm{XXY}$ & gr/gr with DAZ1/2 del \\
19 & 30 & $47, \mathrm{XXY}$ & No \\
23 & 21 & $47, \mathrm{XXY}$ & gr/gr with DAZ1/2 del \\
24 & 26 & $47, \mathrm{XXY}$ & No \\
26 & 28 & $47, \mathrm{XXY}$ & No \\
27 & 27 & $47, \mathrm{XXY}$ & No \\
44 & 37 & $46, \mathrm{X}$ invY (q11.21, q11.22) & b2/b4 deletion \\
51 & 35 & $46, \mathrm{XX}$ male & Complete AZF deletion, +ve SRY \\
54 & 31 & $46, \mathrm{XX}$ male & Complete AZF deletion, +ve SRY \\
\hline
\end{tabular}

chromosomal normality in Y microdeleted cases, data showed in Table 6.

AZFc subdeletion typing analysis was reported that, among the 10 cases, that had AZFc aberrations, five cases had gr/gr subtype with DAZ1/2 deletion (5/10, 50\%), three cases had b2/b4 subtype with DAZ1/2/3/4 deletion (3/10, $30 \%$ ), and two cases (46, XX male with positive SRY gene) accounted as b2/b4 subtype because they had no $\mathrm{Y}$ chromosome. Only one case (case no. 37) had a microdeletion outside the DAZ region, as shown in Table 7 and Figs 1 to 3C.

Regarding total number of cases included in the present study, Yq mapping analysis results were summarized in Table 8.

Therefore, in the azoospermic infertile men included in this study, there was a significant difference between the prevalence of AZFc aberration and AZFa+b aberration and a significant difference between the prevalence of AZFc aberrations combined with reduced DAZ dosage and AZFc aberrations not combined with reduced DAZ dosage.

All normozoospermic fertile men had no detected AZF deletions using the same technique.

\section{DISCUSSION}

It has long been recognized that $\mathrm{Y}$ chromosome microdeletions and chromosomal anomalies are closely related to male infertility. However, few studies have specifically examined the general characteristics of the whole AZF region and its rearrangements in NOA infertile men in Egypt. Additionally, these $\mathrm{Y}$ chromosome microdeletions cannot be predicted cytogenetically, on the basis of clinical findings or by semen analysis. Thus, PCR-based AZF screening for Yq microdeletions is necessary.

In the past, the diagnosis of a genetic etiology had little clinical significance. But recently, with the advent of assisted reproductive technology and our knowledge of the vertical iatrogenic transmission of these genetic anomalies to the offspring, diagnosing the presence of these deletions has become very important. Diagnosis not only aids in determining the prognosis in these infertile cases, but provides the information necessary to counsel these couples effectively, particularly with regard to the birth of infertile male offspring who may have the same or secondary, and larger deletions with more severe testicular phenotype. ${ }^{15}$ 


\begin{tabular}{llcc}
\hline \multicolumn{2}{c}{ Table 6: Chi-square analysis for combining molecular and karyotyping data } \\
\hline $\begin{array}{l}\text { Frequency of sex chromosomal } \\
\text { anomalies in Y microdeleted cases }\end{array}$ & $\begin{array}{l}\text { Frequency of sex chromosomal } \\
\text { normality in Y microdeleted cases }\end{array}$ & \multicolumn{2}{c}{ Chi-square test analysis } \\
\cline { 2 - 4 } & $6 / 11(54.5 \%)$ & $\chi^{2}$ value & $p$-value \\
\hline (45.5\%) & 6al & 0.091 & 0.763 \\
\hline
\end{tabular}

$\S$ Values for $\mathrm{p}$ less than 0.05 were considered statistically significant

\begin{tabular}{|c|c|c|c|c|c|c|c|c|c|c|}
\hline \multirow{3}{*}{$\begin{array}{c}\text { Cases ID } \\
\\
2 \\
2 \\
7\end{array}$} & \multirow{2}{*}{$\begin{array}{l}\text { Karyotyping } \\
46, \mathrm{XY}\end{array}$} & \multicolumn{2}{|c|}{$\begin{array}{c}\text { AZFa del } \\
\text { sY84 } \\
\text { sY86 }\end{array}$} & \multicolumn{2}{|c|}{$\begin{array}{l}\text { AZFb del } \\
\text { sY127 } \\
\text { sY134 }\end{array}$} & \multicolumn{2}{|c|}{$\begin{array}{l}\text { AZFc del } \\
\text { sY254 } \\
\text { sY255 }\end{array}$} & \multirow{2}{*}{$\begin{array}{c}D A Z 1 / 2 \\
\text { del }\end{array}$} & \multirow{2}{*}{$\begin{array}{c}D A Z 3 / 4 \\
\text { del }\end{array}$} & \multirow{2}{*}{$\begin{array}{c}\text { AZFc } \\
\text { subtypes } \\
\text { b2/b4 }\end{array}$} \\
\hline & & - & - & - & - & + & + & & & \\
\hline & $46, X Y$ & & & & & & & & & \\
\hline & $15 p s+12$ & - & - & - & - & + & + & + & + & $\mathrm{b} 2 / \mathrm{b} 4$ \\
\hline 9 & $46, X Y$ & - & - & - & - & - & - & + & - & $\mathrm{gr} / \mathrm{gr}$ \\
\hline 14 & $46, X Y$ & - & - & - & - & - & - & + & - & $\mathrm{gr} / \mathrm{gr}$ \\
\hline 18 & $47, X X Y$ & - & - & - & - & - & - & + & - & $\mathrm{gr} / \mathrm{gr}$ \\
\hline 23 & $47, X X Y$ & - & - & - & - & - & - & + & - & $\mathrm{gr} / \mathrm{gr}$ \\
\hline 28 & $46, X Y$ & - & - & - & - & - & - & + & - & $\mathrm{gr} / \mathrm{gr}$ \\
\hline 37 & $46, X Y$ & + & - & - & + & - & - & - & - & \\
\hline \multirow[t]{2}{*}{44} & $46, x$ inv & & & & & & & & & \\
\hline & $Y(q 11.21, q 11.22)$ & - & - & - & - & + & + & + & + & $\mathrm{b} 2 / \mathrm{b} 4$ \\
\hline \multirow[t]{2}{*}{51} & $\begin{array}{l}\text { 46, XX with } \\
\text { presence of }\end{array}$ & & & & & & & & & \\
\hline & SRY (sY14) & + & + & + & + & + & + & + & + & b2/b4 \\
\hline \multirow[t]{2}{*}{54} & $46, X X$ with & & & & & & & & & \\
\hline & $\begin{array}{l}\text { presence of } \\
\text { SRY (sY14) }\end{array}$ & + & + & + & + & + & + & + & + & b2/b4 \\
\hline
\end{tabular}

+: Sequence-tagged site marker deleted; -: Sequence-tagged site marker present; Del: Deletion

Table 8: Results of Yq mapping analysis for all cases and Chi-square test analysis for all AZF aberrations among deleted azoospermic infertile men

\begin{tabular}{|c|c|c|c|c|}
\hline \multirow[t]{2}{*}{ AZF aberrations } & \multirow{2}{*}{$\begin{array}{l}\text { No. of cases/total } \\
\text { number of cases }\end{array}$} & \multicolumn{2}{|c|}{ Chi-square test analysis } & \multirow[t]{2}{*}{ Percentage } \\
\hline & & $\chi^{2}$ value & $p$-value $e^{\S}$ & \\
\hline AZF & $11 / 54$ & & & 20.4 \\
\hline AZFc only & $8 / 11$ & 7.82 & 0.02 & 72.7 \\
\hline Partial AZFa+b & $1 / 11$ & & & 9.1 \\
\hline All AZF & $2 / 11$ & & & 18.2 \\
\hline $\begin{array}{l}\text { - AZF aberrations } \\
\text { combined with } \\
\text { reduced DAZ } \\
\text { dosage }\end{array}$ & $10 / 11$ & 7.36 & 0.007 & 90.9 \\
\hline $\begin{array}{l}\text { - AZF aberrations } \\
\text { not combined with } \\
\text { reduced DAZ dosage }\end{array}$ & $1 / 11$ & & & 9.1 \\
\hline $\begin{array}{l}\text { AZFc aberrations } \\
\text { combined with }\end{array}$ & & & & \\
\hline reduced DAZ dosage & $8 / 54$ & & & 14.8 \\
\hline - DAZ1/2 del only (gr/gr) & $5 / 8$ & 0.50 & 0.48 & 62.5 \\
\hline - DAZ3/4 del only & $0 / 8$ & & & 0 \\
\hline $\begin{aligned} &- \text { DAZ1/2/3/4 del } \\
& \text { only (b2/b4) }\end{aligned}$ & $3 / 8$ & & & 37.5 \\
\hline
\end{tabular}

§Values for $\mathrm{p}$ less than 0.05 were considered statistically significant

Selection of an appropriate combination of sequence tagged site (STS) loci is critical in the determination of Y-chromosome microdeletion frequency. The European Academy of Andrology and the European Molecular Genetics Quality Network guidelines indicate that the use of six STS loci (sY84, sY86, sY127, sY134, sY254, sY255) results in the detection of up to $95 \%$ of all reported
Y chromosome microdeletions in the AZF regions. ${ }^{9}$ Additional STS loci can then be used to define the deletion breakpoints further.

According to the European Association of Urology Guidelines on Male Infertility (The 2012 update), the highest frequency of classical $\mathrm{Y}$ microdeletions is found in men with azoospermia (8-12\%) followed by those with 


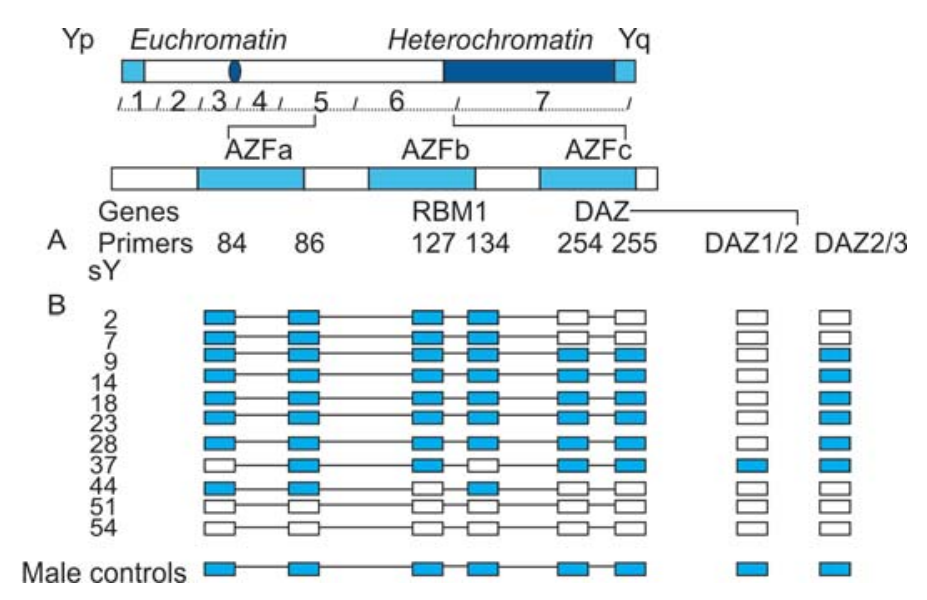

Fig. 1: $Y$ chromosome and deletion intervals for the studied cases: $(A) A$ list of the sequence-tagged sites screened of the AZFa, AZFb and $A Z F C$ regions. RBM1 and DAZ are genes identified in each region, (B) microdeletion maps of positive cases. Blue boxes represent the presence of a STS. White boxes represent the absence of a STS. Map of male controls is demonstrated in the last row

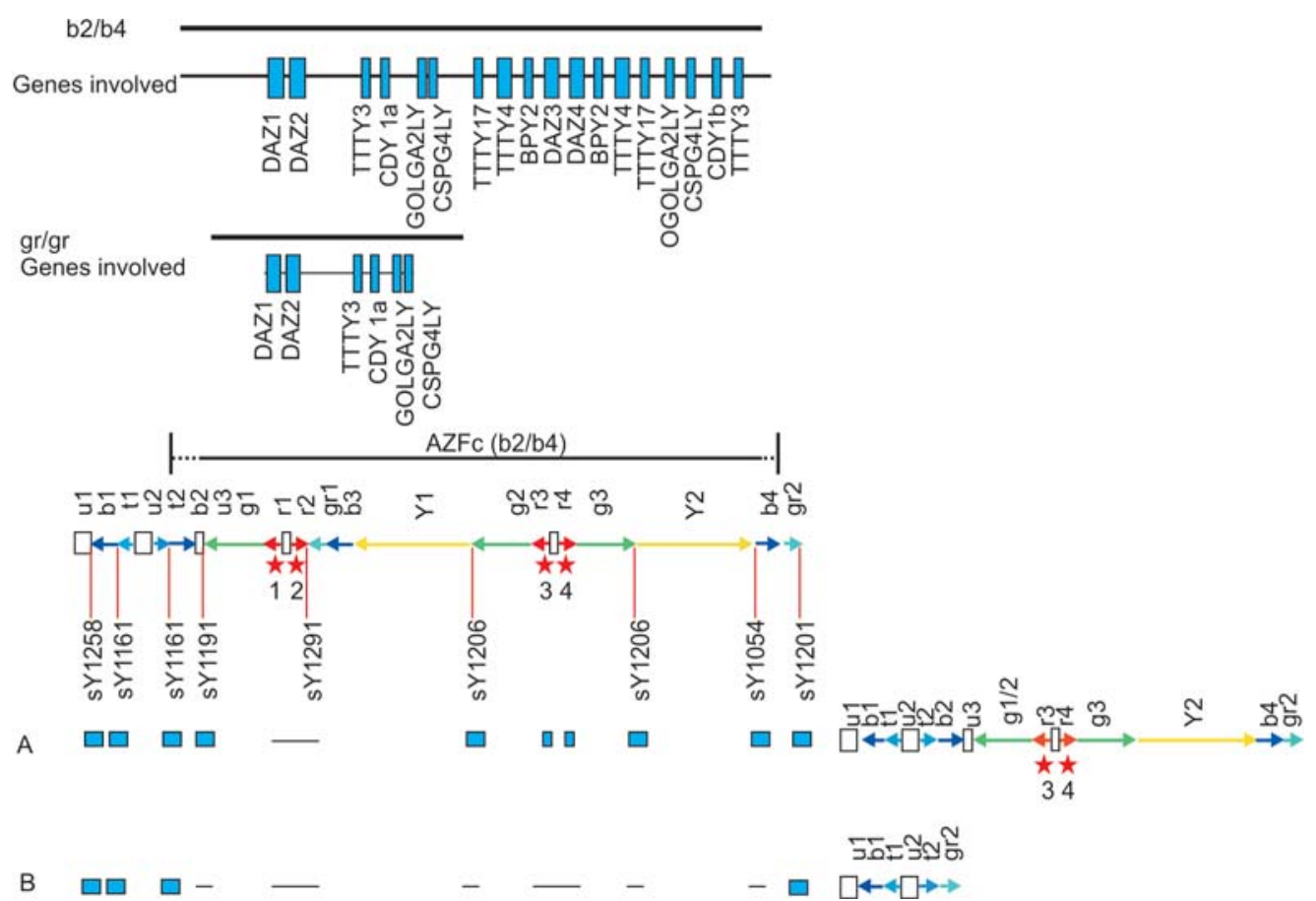

Fig. 2: Schematic representation of our results for AZFc structure, AZFc-specific STS and DAZ-specific SNV analysis. At the top, the ampliconic structure of the AZFc region. Red stars numbered 1 to 4 show the position of the four DAZ genes. Immediately, below are indicated the STSs utilized to detect deletions. Below are the results for STS analysis (on the left) with the resulting organization of AZFc amplicons (on the right). Blue boxes: STS present, and lines-STS absent; (A) gr/gr deletion identified by the absence of sY1291 and DAZ1/2; (B) b2/b4 deletion identified by the presence of sY1201, 1161 and 1258 only

oligozoospermia (3-7\%). ${ }^{16}$ The frequency and type of $\mathrm{Y}$ chromosome microdeletions varied according to ethnic, regional differences, selection criteria for patient samples or methodological differences. ${ }^{17}$

In this study, 20.4\% of the studied Egyptian NOA infertile men had Yq deletions; on the other side, Medica et $\mathrm{al}^{18}$ found no Y chromosome microdeletions in NOA men in Croatia (Europe), India, Taiwan (Asia) and Morocco (Africa). ${ }^{19-21}$

According to EAA/EMQN guidelines (2004 to 2012), about $90 \%$ of NOA men have not any classical Y microdeletions. So in this work, we performed more specific mapping to a whole AZF region to include DAZ gene dosage that was confirmed by AZFc subtypes assay. Therefore, we found a significant prevalence of reduced DAZ gene dosage (90.9\%) among Egyptian NOA men.

Seven studies reported the highest frequency of microdeletions in the AZFc region. ${ }^{15,22-25,26,27}$ This agrees with our findings, where $90 \%$ of Yq deletions are due to AZFc. However, Mafra et al ${ }^{28}$ reported that nonobstructive azoospermic men from Brazil (South America) had no AZFc deletions.

In our study, only one case had partial AZFa+b microdeletion detected, and this agrees with Lin et al, 

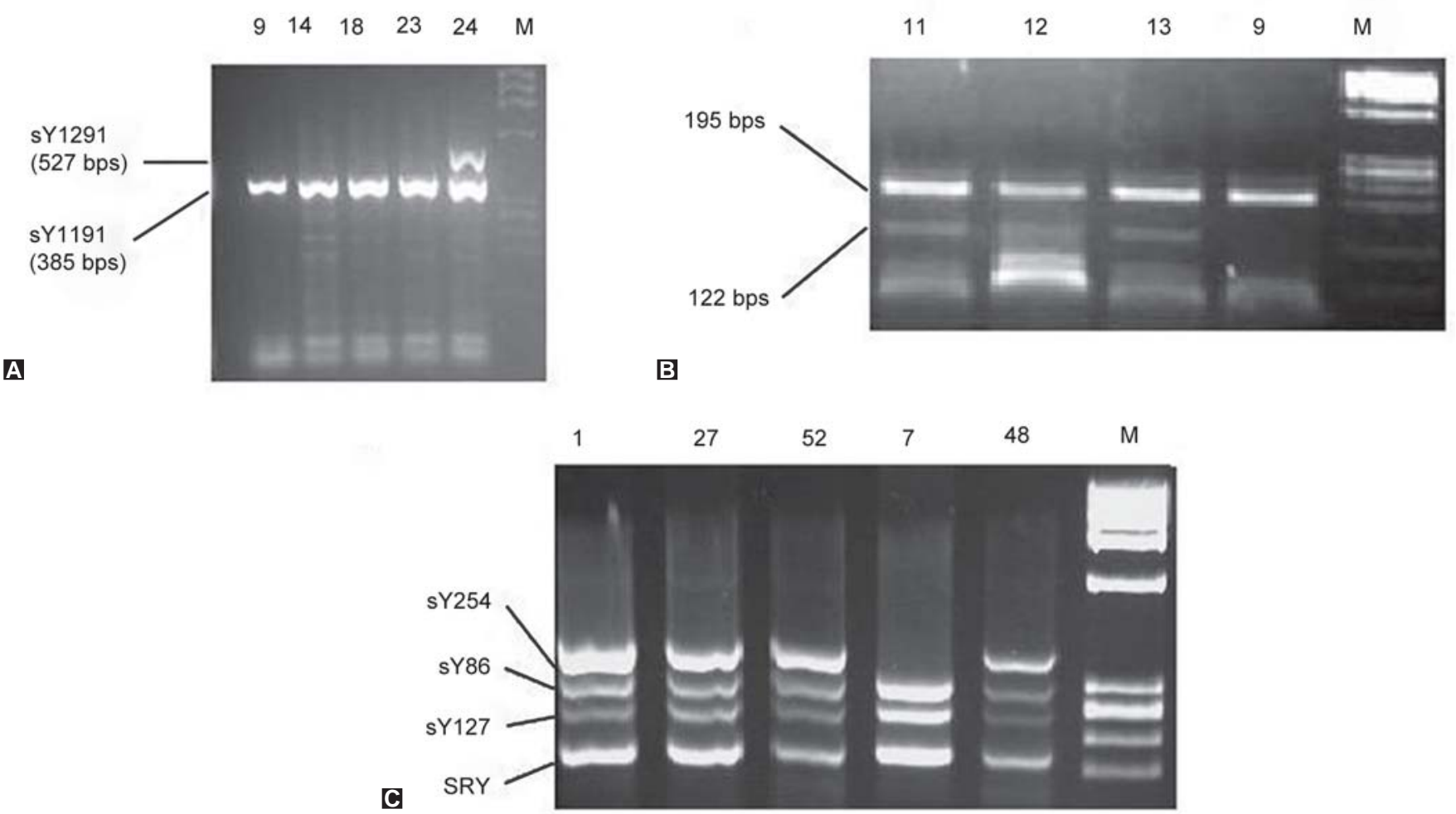

Figs 3A to C: (A) STS \pm multiplex PCR amplified products of sY1291 and sY1191 of AZFc subdeletion showed that cases no. 9, 14, 18 and $23 \mathrm{had}$ gr/gr deletion type, where SY1291 was deleted, (B) agarose gel electrophoresis for restriction enzyme assay by Dra I showed that case no. 9 had absent 122 bps fragment, indicating that DAZ1/2 were deleted, (C) STS \pm multiplex PCR amplified products of sY254, 86, 127 and SRY showed that case no. 7 had sY254 deletion, PHI-174/Hae III marker (M)

Tsujimura et al, Medica et al, Ferlin et al, Imken et al, Mitra et al, Yang et al, Mirfakhraie et al ${ }^{18,19-21,24,26,29,30}$ who reported no AZFb deletions in NOA men. But, our previous finding was on contrast with Foresta et al, Lin et al, Martinez et al, Dada et al, Dai et al ${ }^{15,22,24,25,27}$ which reported that the next highest frequency of microdeletion after AZFc is AZFb, also Le Bourhis et $\mathrm{al}^{23}$ found AZFa microdeletion.

According to our results, we found that certain deletion patterns could be related to the Egyptian cases, where AZFc deletion with reduced DAZ gene copy number accounting $72.7 \%$ of cases had AZF deletion.

We found frequency of a certain STS markers lower in Egyptian cases than China ones, where Dai et $\mathrm{al}^{27}$ reported 94.1\% deletion in sY254 and 94.1\% deletion in sY255, but this work reported 50\% deletion in sY254 and 50\% deletion in sY255.

In this work, the frequency of DAZ1/2 deletion among Egyptian NOA men was $9.3 \%$ and $5.6 \%$ for DAZ1/2/3/4 deletion, and no found any cases had only DAZ2/3 deletion. Therefore, this frequency was considered compatible with others because there are studies which have shown that in the Caucasian population 15\% of idiopathic azoospermia cases had deletion of either 4 DAZ genes or DAZ1/DAZ2 in AZFc region, and $8.8 \%$ of china azoospermic patients had complete deletion of DAZ genes, and DAZ1/DAZ2 deletion was confirmed in 8.3 of azoospermic patients. ${ }^{11,15,31}$
In this work, the recorded increased prevalence of AZFc deletion in infertile men, who had Yq deletions, represents a risk factor for male infertility, and among eight cases had AZFc deletions, mostly were of the gr/gr subtype (62.5\%) followed by b2/4 subtype (37.5\%).

Our findings are in agreement with and further support other preliminary reports done on AZFc deletions. ${ }^{12,31,32}$ These studies suggested that the $\mathrm{gr} / \mathrm{gr}$ deletion and the g1/g2, which remove DAZ copies 1 and 2, represented a risk factor for spermatogenic damage. In contrast, the b2/b3, gr/gr and g1/g3 deletions, which remove DAZ copies 3 and 4, seemed to have no or little effect on fertility.

\section{CONCLUSION AND RECOMMENDATIONS}

To our knowledge, the previous Egyptian studies ${ }^{33-35}$ of male infertility were not investigated AZFc subtypes deletion and DAZ gene copy number variation, so this is the first study manipulated genetic mapping of AZFc region to investigate the prevalence of AZFc subtypes deletion and DAZ gene dosage in Egyptian azoospermic infertile men. Microdeletion analysis using STS \pm multiplex PCR and PCR-RFLP could be sufficient tool to determine the frequency, mapping and site of gene deletion. DAZ genes deletion is a risk factor for spermatogenic damage.

According to this work, the frequency and type of Y chromosome microdeletions varied by ethnic and regional 
differences. So, we recommend adding the DAZ gene dosage investigation in EAA/EMQN classical Y microdeletions protocol for Egyptian NOA cases, especially that DAZ gene abnormality could be transmitted from the father to his offspring after successful intracytoplasmic sperm injection (ICSI). Also, we recommend studying the prevalence of $\mathrm{Y}$ microdeletion in Egyptian NOA infertile men population using more cases and STS markers.

\section{REFERENCES}

1. World Health Organization. WHO manual for the standardized investigation and diagnosis of the infertile couple. Cambridge, UK: Cambridge University Press 2000.

2. Mosher W. Reproductive impairments in the United States 1965-1982. Demography 1985;22:415-30.

3. Tse J, Yeung W, Lau E. Deletions within the azoospermia factor subregions of the Y chromosome in Hong Kong Chinese men with severe male-factor infertility: Controlled clinical study. HKMJ 2000;6:143-46.

4. Anurag M, Rima D, Rajeev K, Gupta N, Kiran K, Gupta S. Screening for Y-chromosome microdeletions in infertile Indian males: Utility of simplified multiplex PCR. Indian J Med Res 2008;127:124-32.

5. Dada R, Thilagavathi J, Venkatesh S, Esteves S, Agarwal A. Genetic testing in male infertility. Open Reprod Sci J 2011;3: 42-56.

6. Verma R, Babu A. Principles and techniques. Human Chromosomes (2nd ed) New York, San Francisco Mc Graw Hill Inc, 1995.

7. Yunis J, Brunning R, Lobell M. High resolution chromosomes as an independent prognostic indicator in adult acute nonlymphocytic leukemia. New Engl J Med 1984;311: 812-18.

8. ISCN: An International System for Human Cytogenetics Nomenclature. Shaffer L, Tommerup N (Eds). S Karger Basel 2005.

9. Simoni M, Bakker E, Krausz C. EAA/EMQN best practice guidelines for molecular diagnosis of Y-chromosomal microdeletions. State of the art 2004. Int J Androl 2004;27:240-49.

10. Lin Y, Hsu C, Yen P. A two-step protocol for the detection of rearrangements at the AZFc region on the human Y chromosome. Mol Hum Reprod 2006;12:347-51.

11. Yuan Y, Cui-ying X, Si-zhong Z, Si-xaio Z, Ming-kong H, Li L. High risk genetic factor in Chinese patients with idiopathic male infertility; deletion of DAZ gene copy on Y chromosome. Chin Med J 2004;117:1092-94.

12. Lu C, Zhang J, Li Y, Xia Y, Zhang F, Wu B, et al. The b2/b3 subdeletion shows higher risk of spermatogenic failure and higher frequency of complete AZFc deletion than the gr/gr subdeletion in a Chinese population. Hum Mol Genet 2009;18: 1122-30.

13. Ferlin A, Tessari A, Ganz F, Marchina E, Barlati S, Garolla A, et al. Association of partial AZFc region deletions with spermatogenic impairment and male infertility. J Med Genet 2005;42:209-13.

14. de Carvalho C, Zuccherato L, Fujisawa M, Shirakawa T, Ribeirodos-Santos A, Santos S, et al. Study of AZFc partial deletion gr/gr in fertile and infertile Japanese males. J Hum Genet 2006;1: 794-99.
15. Dada R, Gupta NP, Kucheria K. Yq microdeletionsazoospermia factor candidate genes and spermatogenic arrest. J Biomol Tech 2004;15:176-83.

16. Jungwirth A, Giwercman A, Tournaye H, Diemer T, Kopa Z, Dohle G, et al. European Association of Urology Guidelines on male infertility: The 2012 Update. Eur Urol 2012;623: 24-332.

17. Krausz C, Forti G, McElreavey K. The Y chromosome and male fertility and infertility. Int J Androl 2003;26:70-75.

18. Medica I, Gligorievska N, Prenc M, Peterlin B. Y microdeletions in the Istria country, Croatia. Asian J Androl 2005;7:213-16.

19. Imken L, El Houate B, Chafik A, Nahili H, Boulouiz R, Abidi O, et al. AZF microdeletions and partial deletions of AZFc region on the Y chromosome in Moroccan men. Asian J Androl 2007;9: 674-78.

20. Mitra A, Dada R, Kumar R, Gupta N, Kucheria K, Gupta. Screening for Y-chromosome microdeletions in infertile Indian males: Utility of simplified multiplex PCR. Ind J Med Res 2008; 127:124-32.

21. Yang Y, Ma M, Xiao C, Li L, Li S, Zhang S. Massive deletion in $\mathrm{AZFb} / \mathrm{b}+\mathrm{c}$ and azoospermia with Sertoli cell only and/or maturation arrest. Int J Androl 2008;31:573-78.

22. Foresta C, Ferlin A, Moro E. Deletion and expression analysis of AZFa genes on the human Y chromosome revealed a major role for DBY in male infertility. Hum Mol Genet 2000;9: 1161-69.

23. Le Bourhis C, Siffroi J, McElreavey K, Dadoune J. Y chromosome microdeletions and germinal mosaicism in infertile males. Mol Hum Reprod 2000;6:688-93.

24. Lin Y, Chen C, Sun H, Hsu C, Chen J, Lin S, et al. Y-chromosome microdeletion and its effect on reproductive decisions in taiwanese patients presenting with nonobstructive azoospermia. Urology 2000;56:1041-46.

25. Martinez M, Bernabe M, Gomez E, Ballesteros A, Landeras S, Glover G, et al. Screening for AZF deletion in a large series of severely impaired spermatogenesis patients. J Androl 2000;21: 651-55.

26. Tsujimura A, Matsumiya K, Takao T, Miyagawa Y, Koga M, Takeyama $\mathbf{M}$, et al. Clinical analysis of patients with azoospermia factor deletions by microdissection testicular sperm extraction. Int J Androl 2004;27:76-81.

27. Dai R, Wang R, Jin J, Niu G, Lee J, Li S, Liu R. Correlation of Y-chromosome multiple segmental deletions and chromosomal anomalies in non-obstructive azoospermic males from northeastern China. Genet Mol Res 2012;10:11.

28. Mafra F, Christofolini D, Bianco B, Gava M, Glina S, Belangero S, et al. Chromosomal and molecular abnormalities in a group of Brazilian infertile men with severe oligozoospermia or non-obstructive azoospermia attending an infertility service. Int Braz J Urol 2011;37:244-50.

29. Ferlin A, Arredi B, Speltra E, Cazzadore C, Selice R, Garolla A, et al. Molecular and clinical characterization of $\mathrm{Y}$-chromosome microdeletions in infertile men: A 10-year experience in Italy. J Clin Endocrinol Metab 2007;92:762-70.

30. Mirfakhraie R, Mirzajani F, Kalantar S, Montazeri M, Salsabili N, Pourmand G, et al. High prevalence of AZFb microdeletion in Iranian patients with idiopathic non-obstructive azoospermia. Ind J Med Res 2010;132:265-70.

31. Fernandes S, Huellen K, Goncalves J, Dukal H, Zeisler J, Raipert D, et al. High frequency of DAZ1/DAZ2 gene deletions in patients wirh severe oligozoospermia. Mol Hum Reprod 2002;8:286-98. 
32. Repping S, Skaletsky H, Brown L, van Daalen S, Korver C, Pyntikova T, et al. Polymorphism for a $1.6 \mathrm{Mb}$ deletion of the human Y chromosome persists through balance between recurrent mutation and haploid selection. Nat Genet 2003;35: 247-51.

33. Hussein R, Helmy N, Amer M, El-Gerzaway A, Fayez A, Ateyah A. Cytogenetic studies and Y-chromosome microdeletion in men with idiopathic azoospermia. Egypt Med J Nat Res Cent 2007;6:3-10.

34. Abobakr R, Mostafa R, Mahmoud S, Abdallah H, Ibrahim G. Detection of azoospermia factor (AZF) microdeletion on $\mathrm{Y}$ chromosome in infertile men with azoospermia or severe oligozoospermia. Egypt J Derm Androl 2009;29.

35. Nowier S, El-sheikh M, Abdel Rasool H, Ismail S. Prevalence of Y chromosome microdeletion in males with azoospermia and severe oligospermia in Egypt. Res J Med Med Sci 2009;4: 189-95.

\section{ABOUT THE AUTHORS}

\section{Alaaeldin Gamal Fayez (Corresponding Author)}

Assistant Researcher, Department of Molecular Genetics and Enzymology, National Research Centre, Giza, Egypt e-mail: afayez_nrc@yahoo.com

\section{Amr Saad El-Sayed}

Professor of Biochemistry, Department of Chemistry, Cairo University, Giza, Egypt

\section{Mohamed Ali El-Desouky}

Lecturer of Biochemistry, Department of Chemistry, Cairo University Giza, Egypt

\section{Waheba Ahmed Zarouk}

Assistant Professor, Department of Molecular Genetics and Enzymology, National Research Centre, Giza, Egypt

\section{Alaa Khalil Kamel}

Professor, Department of Human Cytogenetics, National Research Centre, Giza, Egypt

\section{Ibrahim Mohamed Fahmi}

Professor, Department of Andrology, Cairo University, Giza, Egypt

\section{Mona Omar El-Ruby}

Professor, Department of Clinical Genetics and Cytogenetics, National Research Centre, Giza, Egypt 